\title{
BIRC3 alterations in chronic and B-cell acute lymphocytic leukemia patients
}

\author{
EYAD ALHOURANI ${ }^{1}$, MONEEB A.K. OTHMAN ${ }^{1}$, JOANA B. MELO ${ }^{2,3}$, ISABEL M. CARREIRA ${ }^{2,3}$, \\ BEATA GRYGALEWICZ ${ }^{4}$, DRAGANA VUJIĆ ${ }^{5,6}$, ZELJKO ZECEVIĆ ${ }^{6}$, GORDANA JOKSIĆ $^{7}$, \\ ANITA GLASER ${ }^{1}$, BEATE POHLE $^{1}$, CORDULA SCHLIE $^{1}$, SVEN HAUKE $^{8}$ and THOMAS LIEHR ${ }^{1}$ \\ ${ }^{1}$ Institute of Human Genetics, Jena University Hospital, Friedrich Schiller University, Jena D-07743, Germany; \\ ${ }^{2}$ Laboratory of Cytogenetics and Genomics, Faculty of Medicine, University of Coimbra; \\ ${ }^{3}$ Research Centre for Environment, Genetics and Oncobiology, Coimbra 3000-548, Portugal; \\ ${ }^{4}$ Cytogenetic Laboratory, Maria Sklodowska-Curie Memorial Cancer Centre and Institute, \\ Warsaw 02-781, Poland; ${ }^{5}$ Faculty of Medicine, University of Belgrade, Belgrade 11000; \\ ${ }^{6}$ Institute for Medical Care of Mother and Child of Serbia 'Dr Vukan Cupic', Belgrade 11070; \\ ${ }^{7}$ Vinca Institute of Nuclear Sciences, Belgrade 11001, Serbia; ${ }^{8}$ ZytoVision GmbH, Bremerhaven D-27572, Germany
}

Received March 23, 2015; Accepted December 10, 2015

DOI: $10.3892 / \mathrm{ol} .2016 .4388$

\begin{abstract}
Deletions within chromosome 11q22-23, are considered among the most common chromosomal aberrations in chronic lymphocytic leukemia (CLL), and are associated with a poor outcome. In addition to the ataxia telangiectasia mutated (ATM) gene, the baculoviral IAP repeat-containing 3 (BIRC3) gene is also located in the region. BIRC3 encodes a negative regulator of the non-canonical nuclear factor $\kappa$-light-chain-enhancer of activated B cells $(\mathrm{NF}-\kappa \mathrm{B})$ protein. Disruption of BIRC3 is known to be restricted to CLL fludarabine-refractory patients. The aim of the present study was to determine the frequency of copy number changes of BIRC3 and to assess its association with two known predictors of negative CLL outcome, ATM and tumor protein 53 (TP53) gene deletions. To evaluate the specificity of BIRC3 alterations to CLL, BIRC3 copy numbers were assessed in 117 CLL patients in addition to $45 \mathrm{~B}$-cell acute lymphocytic leukemia (B-ALL) patients. A commercially available multiplex ligation dependent probe amplification kit, which includes four probes for the detection of TP53 and four probes for ATM gene region, was applied. Interphase-directed fluorescence in situ hybridization was used to apply commercially available probes for BIRC3, ATM and TP53. High resolution array-comparative genomic hybridization was conducted in selected cases. Genetic abnormalities of BIRC3 were detected in 23/117 ( 20\%) of CLL and 2/45 ( 4\%) of B-ALL cases. Overall, 20 patients with CLL
\end{abstract}

Correspondence to: Dr Thomas Liehr, Institute of Human Genetics, Jena University Hospital, Friedrich Schiller University, Kollegiengasse 10, Jena D-07743, Germany

E-mail: thomas.liehr@med.uni-jena.de

Key words: chronic lymphocytic leukemia, B-cell acute lymphocytic leukemia, baculoviral IAP repeat-containing 3 gene, copy number alterations, deletion, duplication, hyperdiploidy and 1 with B-ALL possessed a BIRC3 deletion, whilst 3 patients with CLL and 1 with B-ALL harbored a BIRC3 duplication. All patients with an ATM deletion also carried a BIRC3 deletion. Only 2 CLL cases possessed deletions in BIRC3, ATM and TP53 simultaneously. Evidently, the deletion or duplication of $B I R C 3$ may be observed rarely in B-ALL patients. BIRC3 duplication may occur in CLL patients, for which the prognosis requires additional studies in the future. The likelihood that TP53 deletions occur simultaneously with BIRC3 and/or ATM aberrations is low. However, as $A T M$ deletions may, but not always, associate with $B I R C 3$ deletions, each region should be considered in the future diagnostics of CLL in order to aid treatment decisions, notably whether to treat with or without fludarabine.

\section{Introduction}

Chronic lymphocytic leukemia (CLL) is the most common type of leukemia observed in people aged $>50$ years in Western countries. CLL is characterized by a heterogeneous clinical course, with a time to progression ranging from months to decades (1). The presence of cytogenetic abnormalities is a hallmark of CLL. The most common recurrent aberrations in CLL affect chromosomes 11q, 13q, 14q, 17p and the whole of chromosome 12. Certain abnormalities, including deletions in 11q22.3, the ataxia telangiectasia mutated (ATM) gene (10-20\% of all CLL cases), and 17p13.1, the tumor protein 53 (TP53) gene $(5-10 \%$ of all CLL cases), are associated with a poor clinical outcome. Therefore, the detection of these aberrations is important for identifying high-risk patients, who suffer from rapid disease progression and a decreased overall survival time (2). Other frequent chromosomal aberrations in CLL are associated with a good (deletions in $13 q 14$ or 14q32.33) or intermediate (trisomy 12) prognosis (1,3-5).

CLL is considered to be an insidious disease. Certain CLL patients, particularly patients with a good prognosis, survive for several years without requiring treatment; however, another 
subgroup of patients experience an aggressive disease course and have a short life expectancy, despite aggressive treatment (6). The latter group tends to exhibit a particular lack of response to fludarabine-based regimens, which are generally considered to be the first line of treatment for CLL (6). In a large fraction of these patients, the molecular basis of the aggressive clinical course remains unclear; however, in $\sim 40 \%$ of patients, the molecular basis is hypothesized to be due to TP53 disruption (7). In addition, activation of the nuclear factor $\kappa$-light-chain-enhancer of activated B cells (NF- $\kappa \mathrm{B})$ pathway is considered to be a mechanism of resistance to disease eradication (7).

From a clinical perspective, CLL cases may be divided into three major clinical phases: i) newly diagnosed CLL; ii) progressive CLL; and iii) relapsed or fludarabine-refractory CLL. TP53 abnormalities are observed in $40-50 \%$ of relapsed and fludarabine-refractory CLL cases and the deletion of 11q22-23 occurs in $25-30 \%$ of relapsed or fludarabine-refractory CLL patients (8). In a large previous study, 637 patients were classified into four risk groups according to a multivariate analysis of overall survival, which was based on genomic abnormalities and the mutational status of TP53, baculoviral IAP repeat-containing 3 (BIRC3), translocation-associated notch homolog 1 and splicing factor 3B subunit 1. Notably, the high-risk group was composed of patients that exhibited disruption to TP53 and/or BIRC3 (9).

In CLL, deletions within the long arm of chromosome 11 may be highly variable in size. The deletion may be distinguished as the more common 'classical or large deletion' or an 'atypical or small deletion', which is uncommon and more frequently associated with ATM mutations. This variation indicates that other genes may contribute to the pathobiology of $11 \mathrm{q}$ deletions in CLL, and one of the genes that is hypothesized to be involved is BIRC3 (10). BIRC3 disruption, mutations or deletions are rarely detected in CLL at diagnosis (4\% of patients), but are detected in $24 \%$ of fludarabine-refractory CLL patients. In a previous study, fludarabine-sensitive patients did not exhibit BIRC3 mutations initially, which suggests that BIRC 3 disruption may be specifically associated with a chemo-refractory CLL subtype (7). Therefore, BIRC3 disruption may be added to the panel of cytogenetic abnormalities, as it may be helpful in the early identification of relapsed and fludarabine-refractory CLL patients. Affected patients should be considered for other treatment regimens, including cyclin-dependent kinase inhibitor, Bruton's tyrosine-kinase inhibitor, B-cell lymphoma 2 inhibitor or and alemtuzumab/corticosteroids $(8,10)$. BIRC3 abnormalities provide a molecular rationale for using $N F-\kappa B$ inhibitors, which remain under development (7).

\section{Materials and methods}

Patients and sample preparation. The present study included 117 CLL patients, and 45 B-cell acute lymphocytic leukemia (B-ALL) patients that were diagnosed according to standard criteria (11). The samples were obtained with the informed consent from the corresponding patients and according to the institutional Ethical Committee guidelines. For CLL cases, DNA was extracted from lymphocytes using the Gentra ${ }^{\circledR}$ Puregene ${ }^{\circledR}$ Blood kit (Qiagen, Hilden, Germany), according to the manufacturer's protocol. For B-ALL cases, DNA was derived from cytogenetically prepared cells, as previously described (2), which were fixed in methanol/acetic acid (dilution, 3:1) (Table I).
Interphase fluorescence in situ hybridization (iFISH) analysis. iFISH analyses were performed as previously described (2), using the following commercially available probes: LSI p53/LSI ATM (in 17p13.1 and 11q22.3), CEP 3 (D3Z1 in 3p11.1-q11.1), CEP 4 (D4Z1 in 4p11-q11), CEP 7 (D7Z1 in 7p11.1-q11.1), CEP 11 (D11Z1 in 11p11.11-q11), CEP 16 (D16Z2 in 16p11.1-q11.1), CEP 17 (D17Z1 in 17p11.1-q11.1) and CEP 18 (D18Z1 in 18p11.1-q11.1), all from Vysis (Abbott GmbH \& Company, KG, Wiesbaden, Germany); and ZytoLight ${ }^{\circledR}$ SPEC BIRC3/MALT1 DualColor Dual Fusion probe (in 11q22.2 and 18q21.32) from ZytoVision GmbH (Bremerhaven, Germany). For each iFISH analysis, 100-200 interphase nuclei were examined per patient and probe.

Multiplex ligation-dependent probe amplification (MLPA) analysis. MLPA was performed using the SALSA MLPA probemix P377-A1 for Hematological Malignancies kit (MRC-Holland, Amsterdam, Netherlands). The P377-A1 probemix kit contains 52 probes for 37 genes. The TP53 and $A T M$ genes were assessed by four probes each; however, probes for the BIRC3 gene were not included in the kit (2). MLPA was successfully performed on $85 / 117$ CLL samples and 32/45 B-ALL samples. MLPA was not successful for the remaining samples due to fragmentation of DNA.

Array-comparative genomic hybridization (aCGH). aCGH was performed using the Agilent SurePrint G3 Human Genome Microarray $180 \mathrm{~K}$ (Agilent Technologies, Santa Clara, CA, USA), as previously described (12). aCGH was applied in a total of 3 CLL patients that carried a BIRC3 duplication and in $1 \mathrm{~B}-\mathrm{ALL}$ patient that possessed a BIRC3 deletion.

\section{Results}

Gene copy numbers. BIRC3 gene copy number variations were detected in 23/117 ( 20\%) of CLL and 2/45 ( 4\%) of B-ALL cases, as summarized and detailed in Fig. 1. BIRC3 deletions were identified in 20 cases of CLL (cases C-1 to C-20) and in 1 case of B-ALL (case A-1). ATM deletion was detected in the identical $20 \mathrm{CLL}$ and $1 \mathrm{~B}$-ALL cases. Therefore, all patients with a BIRC 3 deletion also possessed an ATM deletion. However, in cases C-1, C-8, C-10, C-13 and C-20 the detected clone sizes with deletions in BIRC 3 and ATM were extremely varied from one another. In case $\mathrm{C}-1$, the clone with the $A T M$ deletion was $8 \mathrm{x}$ smaller compared with that with the BIRC3 deletion, whereas in cases C-8, C-10, C-13 and C-20, the clone with the BIRC3 deletion was $2-3 \mathrm{x}$ smaller than that with the ATM deletion. A BIRC3 duplication was identified in 1 case of B-ALL (case A-2) and in 3 CLL patients (cases C-21 to $\mathrm{C}-23)$ (Table II).

With regard to TP53 abnormalities, 3 patients with B-ALL possessed a TP53 deletion in the absence of any aberrations in BIRC3. TP53 deletions were present in 11 CLL patients, 7 of which possessed no associated BIRC3 aberrations and, notably, 2 of which were accompanied by BIRC3 and ATM amplification.

BIRC3 duplication. In total, 3 CLL patients harbored a BIRC3 duplication (cases C-21 to C-23), 2 of which (C-21 and C-22) were accompanied by ATM and MALT1 duplications 
Table I. Gender, age and cytogenetic results of the B-ALL and CLL cases used in the present study.

Case no. Gender Age, years DNA extracted from Cytogenetic results

\begin{tabular}{lccc}
\hline A-1 & Male & 84 & BM \\
A-2 & Male & 23 & BM \\
A-3 & Male & 34 & BM \\
A-4 & Male & 19 & BM \\
A-5 & Female & 76 & BM \\
C-1 & Male & 73 & BM
\end{tabular}

$\begin{array}{lll}\text { C-2 } & \text { Female } & 50 \\ \text { C-3 } & \text { Female } & 39\end{array}$

C-4

C-5

C-6

C-7

C-8

C-9

C-10

C-11

C-12

C-13

C-14

C-15

C-16

C-17

C-18

C-19

C-20

C-21

C-22

C-23

C-24

C-25

C-26

C-27

C-28

C-29

C-30

C-31

\section{Male}

Male

Male

Male

Male

Male

Male

Male

Female

Male

Male

Male

Male

Female

Male

Male

Male

Male

83

Male

Male

Female

Female

Male

Female

Female

74

74
B

BM

BM
BM
BM
BM
BM

\section{BM}

BM

M

BM

BM

BM

BM

BM

BM

BM

B

BM

B

BM

BM

BM

BM

BM

BM

B

$\mathrm{BM}$

$\mathrm{BM}$

B

B

B

$\mathrm{BM}$

B

$\mathrm{BM}$

B

$\mathrm{BM}$

$\mathrm{BM}$
46,XY,-9,t(9;22)(q34;q11), del(11)(q),+mar[cp3]/46,XY[5]

Hyperdiploid/46,XY

46,XY

$46, X Y$

$45, X,-X[14] / 46, X X[2]$

46-47,XY,del(11)(q22q2?3),add(17)t(17;?)(p11.2;?)[cp5]/

45-46,XY,del(11)(q22q2?3),del(17)(p11.2)[cp4]/

43-46,XY,del(11)(q22q2?3)[cp2]/

$46, X Y[7]$

n.a.

43-46,XY,del(11)(q2?2q2?4)[cp5]/

45-46,XY,del(11)(q2?2q2?4),del(15)(q1?1q2?3)[cp11]/

$46, X Y[1]$

$46, X Y$

46,XY

46,XY

46,XY,del(11)(q?21), add(20)(p13)[7]/

$45, X,-Y[10] / 46, X Y[3]$

46,XY

n.a.

45,XY,der(2)t(2;13)(q?37;q?14),?del(6)(p?23),

$\operatorname{del}(11)(q ? 21) \operatorname{der}(12) t(12 ; 13)(q ? 24 ; q ? 22),-13[\mathrm{cp} 4] /$ 46,XY[19]

n.a.

46,XX,add(11)(q?22)[3]/ 46,XX[12]

46,XY

46,XY

46,XY

n.a.

46,XX[18]

$45, X,-X[1]$

n.a.

46,XY

45-46,XY,del(11)(q?22q?23)[cp14]

$46, X Y[5]$

47,XY,-11,+12,+mar[cp3]/

47,XY,del(5)(p1?3),-11,+12,-17,+mar1,+mar2[cp6]/ $46, X Y[9]$

$46, X Y$

46,XY

n.a.

46,XX

$46, X Y, ? \mathrm{t}(3 ; ?)(\mathrm{p} 21 ; ?), \operatorname{add}(17)(\mathrm{p} ? 12) \operatorname{ort}(17 ; ?),-8,+\operatorname{mar}[\mathrm{cp} 7]$ $46, X Y[9]$

46,XX

$46, X X, i(17)(q 10)[1] / 46, X X,+12, i(17)(q 10),-21[9] /$

$46, X X, t(3 ; ?)(q 2 ? 9 ; ?)[4],-7[4],+12[4], \mathrm{i}(17)(\mathrm{q} 10)[4][\mathrm{cp} 4] /$ $46, \mathrm{XX}[4]$

n.a.

n.a.

$46, \mathrm{XX}$

A-, B-ALL case; C-, CLL case; BM, cell pellet in Carnoys fixative from bone marrow; B, blood; n.a., data not available. 
Table II. Summary of MLPA and iFISH results of TP53, ATM, BIRC3 and MALT1 in all studied cases.

\begin{tabular}{|c|c|c|c|c|c|c|}
\hline \multirow[b]{2}{*}{ Case no. } & \multicolumn{2}{|c|}{ TP53 (\%) } & \multicolumn{2}{|c|}{$A T M(\%)$} & \multirow{2}{*}{$\begin{array}{c}\text { BIRC3 (\%) } \\
\text { iFISH }\end{array}$} & \multirow{2}{*}{$\begin{array}{c}\text { MALTI (\%) } \\
\text { iFISH }\end{array}$} \\
\hline & MLPA & iFISH & MLPA & iFISH & & \\
\hline A-1 & $\mathrm{N}$ & $\mathrm{N}$ & $\mathrm{D}$ & $\mathrm{D}(76.5)$ & $\mathrm{D}(75.0)$ & $\mathrm{N}$ \\
\hline A-2 & n.a. & $\mathrm{A}(100.0)$ & n.a. & $\mathrm{A}(100.0)$ & A (100.0) & $\mathrm{A}(100.0)$ \\
\hline A-3 & $\mathrm{D}$ & $\mathrm{D}(8.5)$ & $\mathrm{N}$ & $\mathrm{N}$ & $\mathrm{N}$ & $\mathrm{N}$ \\
\hline A-4 & $\mathrm{D}$ & $\mathrm{D}(10.0)$ & $\mathrm{N}$ & $\mathrm{N}$ & $\mathrm{N}$ & $\mathrm{N}$ \\
\hline A-5 & D & D (10.0) & $\mathrm{N}$ & $\mathrm{N}$ & $\mathrm{N}$ & $\mathrm{N}$ \\
\hline A-6 to A-33 & $\mathrm{N}$ & $\mathrm{N}$ & $\mathrm{N}$ & $\mathrm{N}$ & $\mathrm{N}$ & $\mathrm{N}$ \\
\hline A-34 to A-45 & n.a. & $\mathrm{N}$ & n.a. & $\mathrm{N}$ & $\mathrm{N}$ & $\mathrm{N}$ \\
\hline $\mathrm{C}-1$ & $\mathrm{D}$ & $\mathrm{D}(86.0)$ & $\mathrm{D}$ & $\mathrm{D}(11.0)$ & $\mathrm{D}(80.0)$ & $\mathrm{N}$ \\
\hline $\mathrm{C}-2$ & $\mathrm{D}$ & $\mathrm{D}(21.0)$ & $\mathrm{N}$ & $\mathrm{D}(23.0)$ & $\mathrm{D}(22.0)$ & $\mathrm{N}$ \\
\hline $\mathrm{C}-3$ & $\mathrm{~N}$ & $\mathrm{~N}$ & $\mathrm{D}$ & $\mathrm{D}(98.0)$ & $\mathrm{D}(90.0)$ & $\mathrm{N}$ \\
\hline C-4 & $\mathrm{N}$ & $\mathrm{N}$ & $\mathrm{D}$ & D (23.5) & $\mathrm{D}(30.0)$ & $\mathrm{N}$ \\
\hline C-5 & $\mathrm{N}$ & $\mathrm{N}$ & $\mathrm{D}$ & D (24.0) & $\mathrm{D}(25.0)$ & $\mathrm{N}$ \\
\hline C-6 & $\mathrm{N}$ & $\mathrm{N}$ & $\mathrm{D}$ & D (88.0) & $\mathrm{D}(85.0)$ & $\mathrm{N}$ \\
\hline C-7 & $\mathrm{N}$ & $\mathrm{N}$ & D & D (90.0) & $\mathrm{D}(80.0)$ & $\mathrm{N}$ \\
\hline C-8 & $\mathrm{N}$ & $\mathrm{N}$ & $\mathrm{D}$ & D (77.0) & $\mathrm{D}(50.0)$ & $\mathrm{N}$ \\
\hline C-9 & $\mathrm{N}$ & $\mathrm{N}$ & $\mathrm{D}$ & $\mathrm{D}(98.0)$ & $\mathrm{D}(75.0)$ & $\mathrm{N}$ \\
\hline C-10 & $\mathrm{N}$ & $\mathrm{N}$ & D & D (87.0) & $\mathrm{D}(60.0)$ & $\mathrm{N}$ \\
\hline C-11 & $\mathrm{N}$ & $\mathrm{N}$ & $\mathrm{D}$ & D (95.0) & $\mathrm{D}(90.0)$ & $\mathrm{N}$ \\
\hline$C-12$ & $\mathrm{~N}$ & $\mathrm{~N}$ & $\mathrm{D}$ & D (83.0) & $\mathrm{D}(80.0)$ & $\mathrm{N}$ \\
\hline C-13 & $\mathrm{N}$ & $\mathrm{N}$ & $\mathrm{D}$ & $\mathrm{D}(93.0)$ & $\mathrm{D}(25.0)$ & $\mathrm{N}$ \\
\hline C-14 & $\mathrm{N}$ & $\mathrm{N}$ & $\mathrm{N}$ & D (33.0) & $\mathrm{D}(15.0)$ & $\mathrm{N}$ \\
\hline$C-15$ & $\mathrm{~N}$ & $\mathrm{~N}$ & $\mathrm{~N}$ & $\mathrm{D}(12.0)$ & $\mathrm{D}(13.0)$ & $\mathrm{N}$ \\
\hline C-16 & n.a. & $\mathrm{N}$ & n.a. & $\mathrm{D}(80.0)$ & $\mathrm{D}(78.0)$ & $\mathrm{N}$ \\
\hline C-17 & n.a. & $\mathrm{N}$ & n.a. & $\mathrm{D}(10.0)$ & $\mathrm{D}(9.0)$ & $\mathrm{N}$ \\
\hline C-18 & n.a. & $\mathrm{N}$ & n.a. & D (73.0) & $\mathrm{D}(64.0)$ & $\mathrm{N}$ \\
\hline $\mathrm{C}-19$ & n.a. & $\mathrm{N}$ & n.a. & $\mathrm{D}(9.0)$ & $\mathrm{D}(10.0)$ & $\mathrm{N}$ \\
\hline $\mathrm{C}-20$ & n.a. & $\mathrm{N}$ & n.a. & $\mathrm{D}(96.0)$ & $\mathrm{D}(42.0)$ & $\mathrm{N}$ \\
\hline C-21 & $\mathrm{D}$ & D (16.0) & $\mathrm{N}$ & $\mathrm{A}(50.0)$ & $\mathrm{A}(50.0)$ & $\mathrm{A}(50.0)$ \\
\hline $\mathrm{C}-22$ & $\mathrm{D}$ & $\mathrm{D}(40.0)$ & $\mathrm{N}$ & $\mathrm{A}(40.0)$ & $\mathrm{A}(40.0)$ & $\mathrm{A}(40.0)$ \\
\hline $\mathrm{C}-23$ & $\mathrm{~N}$ & $\mathrm{~N}$ & $\mathrm{~N}$ & $\mathrm{~N}$ & $\mathrm{~A}(36.0)$ & $\mathrm{N}$ \\
\hline C-24 & $\mathrm{D}$ & D (19.0) & $\mathrm{N}$ & $\mathrm{N}$ & $\mathrm{N}$ & $\mathrm{N}$ \\
\hline $\mathrm{C}-25$ & $\mathrm{D}$ & D (36.0) & $\mathrm{N}$ & $\mathrm{N}$ & $\mathrm{N}$ & $\mathrm{N}$ \\
\hline C-26 & $\mathrm{D}$ & $\mathrm{D}(89.0)$ & $\mathrm{N}$ & $\mathrm{N}$ & $\mathrm{N}$ & $\mathrm{N}$ \\
\hline C-27 & $\mathrm{D}$ & D (77.0) & $\mathrm{N}$ & $\mathrm{N}$ & $\mathrm{N}$ & $\mathrm{N}$ \\
\hline C-28 & $\mathrm{D}$ & $\mathrm{D}(95.0)$ & $\mathrm{N}$ & $\mathrm{N}$ & $\mathrm{N}$ & $\mathrm{N}$ \\
\hline C-29 & $\mathrm{N}$ & $\mathrm{D}(11.5)$ & $\mathrm{N}$ & $\mathrm{N}$ & $\mathrm{N}$ & $\mathrm{N}$ \\
\hline C-30 & n.a. & $\mathrm{D}(86.5)$ & n.a. & $\mathrm{N}$ & $\mathrm{N}$ & $\mathrm{N}$ \\
\hline C-31 & $\mathrm{N}$ & $\mathrm{N}$ & $\mathrm{N}$ & $\mathrm{N}$ & $\mathrm{N}$ & $\mathrm{A}(75.0)$ \\
\hline C-32 to C-91 & $\mathrm{N}$ & $\mathrm{N}$ & $\mathrm{N}$ & $\mathrm{N}$ & $\mathrm{N}$ & $\mathrm{N}$ \\
\hline C-92 to C-117 & n.a. & $\mathrm{N}$ & n.a. & $\mathrm{N}$ & $\mathrm{N}$ & $\mathrm{N}$ \\
\hline
\end{tabular}

Data are expressed as type of change to copy number (\% of cells with aberration). TP53, tumor protein 53; ATM, ataxia telangiectasia mutated; BIRC3, baculoviral IAP repeat-containing 3; MALT1, mucosa-associated lymphoid tissue lymphoma translocation gene 1; MLPA, multiplex ligation-dependent probe amplification; iFISH, interphase fluorescence in situ hybridization; A-, B-ALL case; C-, CLL case; N, no aberration; D, deletion; A, amplification; n.a., data not available.

in addition to TP53 deletion. To study these cases in greater depth, iFISH was performed using centrometric probes for chromosomes (CEP) 3, 4, 7, 11, 16 and 18. For these chromosomes, 3 signals were detected in $11 \%$ (case C-21) and $25 \%$ (case C-22) of the cells, and 4 signals were detected in $29 \%$ (case C-21) and 25\% (C-22) of the cells, respectively (Fig. 2).

The third CLL case (C-23) with BIRC3 duplication was associated with normal copy numbers of TP53 and ATM; the 
A

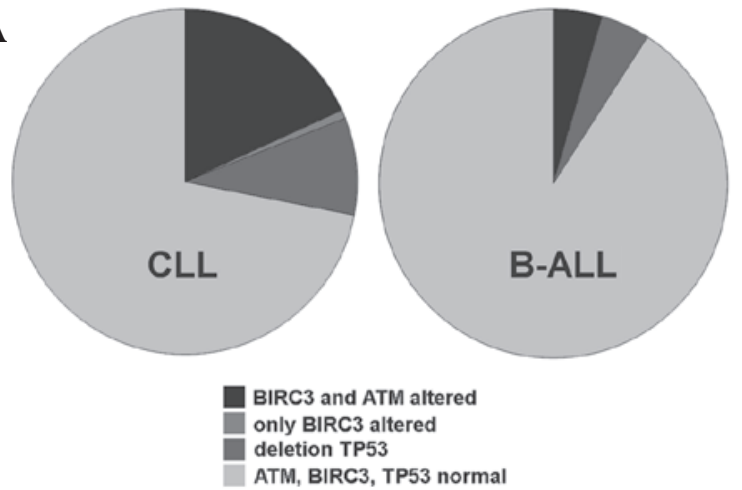

B

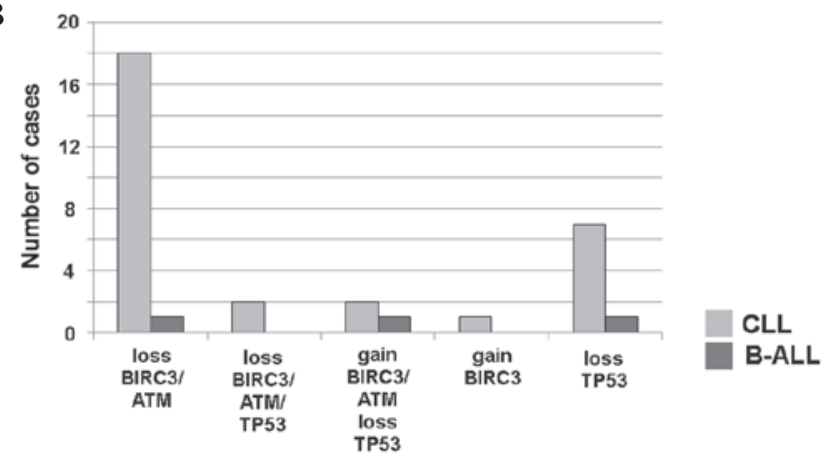

Figure 1. The distribution and of BIRC3, ATM and TP53 aberrations in CLL and B-ALL patients are summarized. (A) In CLL and B-ALL, the majority of patients did not show alterations in the three genes. Distribution of the loss and gain of copy numbers in the two patient groups is depicted. (B) Combinations of loss and gain of the three genes were identified in the patients with CLL and B-ALL, with alterations from part (A). BIRC3, baculoviral IAP repeat-containing 3; ATM, ataxia telangiectasia mutated; TP53, tumor protein 53; CLL, chronic lymphocytic leukemia; B-ALL, B-cell acute lymphocytic leukemia.

$\mathbf{A}$

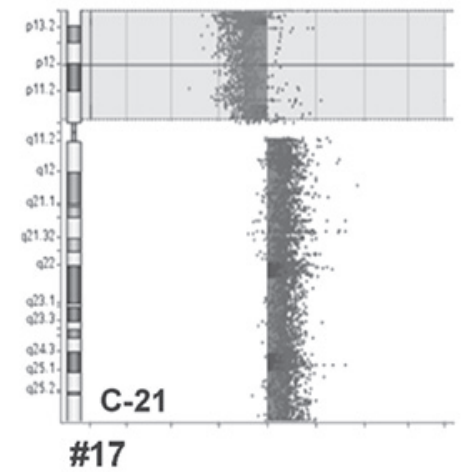

B

B

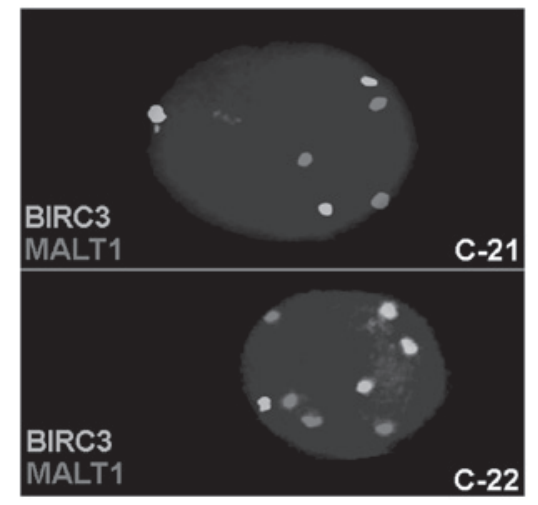

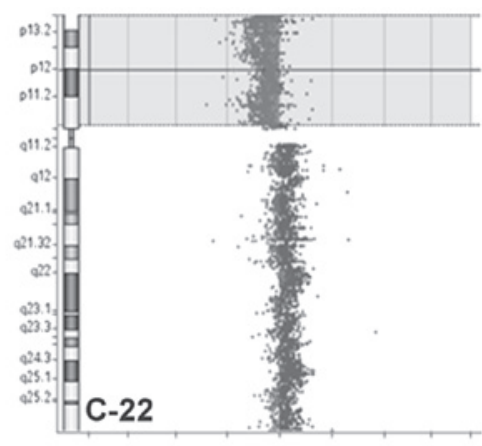

\#17

C

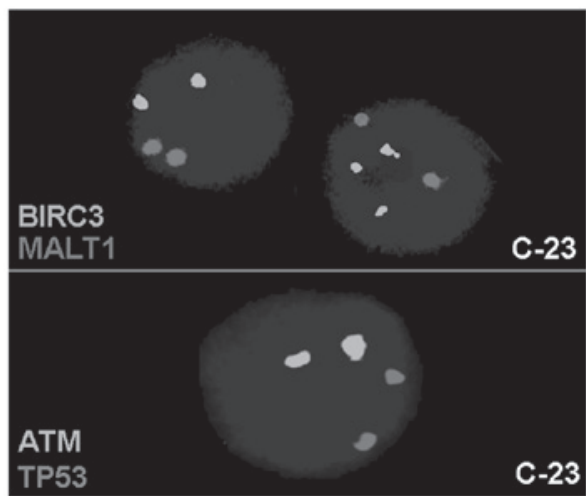

Figure 2. (A) Array comparative genomic hybridization confirmed the deletion in TP53, which was detected initially using iFISH and multiplex ligation dependent probe amplification for CLL cases C-21 and C-22. The whole short arm was deleted and the long arm was possibly duplicated due to an isochromosome 17 formation, at least in case C-21. (B) Examples for gain of copy numbers for BIRC3 and MALT1 in the 2 cases by iFISH: i) C-21, an example of 3 copies and ii) C-22, an example of 4 copies. (C) iFISH results of the CLL case C-23. BIRC3 had 3 copies in certain cells; however ATM, MALT1 and TP53 exhibited only 2 copies each, in all cells. TP53, tumor protein 53; CLL, chronic lymphocytic leukemia; iFISH, interphase fluorescence in situ hybridization; BIRC3, baculoviral IAP repeat-containing 3; MALT1, mucosa-associated lymphoid tissue lymphoma translocation gene 1; ATM, ataxia telangiectasia mutated.

centromeric probes for chromosomes 11 and 17 only revealed 2 signals each (Fig. 2).

Based on the aCGH results for cases C-21, C-22 and C-23, the TP53 deletion in $\mathrm{C}-21$ and $\mathrm{C}-22$ was confirmed; however, BIRC3 was normal in all 3 patients (Fig. 2). Therefore, cases C-21 and C-22 had a mixture of a malignant triploid and tetraploid cell clones and a deletion in TP53. Case C-23 demonstrated the selective gain of copy numbers for BIRC3, without ATM involvement, in $36 \%$ of the cells; however, this finding was not detectable using aCGH.
MALT1 duplication. The patient with a MALT1 duplication (case C-31) possessed an acquired trisomy of chromosome 18, which was confirmed using MLPA and iFISH. The probes for the deleted in colorectal cancer gene on 18q21.2 and RNA (guanine-7-)methyltransferase gene on 18p11.22 revealed a duplication by MLPA, which was confirmed by iFISH in $75 \%$ of the cells.

$B$-ALL patients. Regarding B-ALL patients, 1 case revealed a deletion in BIRC3 along with ATM (case A-1), and another case 
A

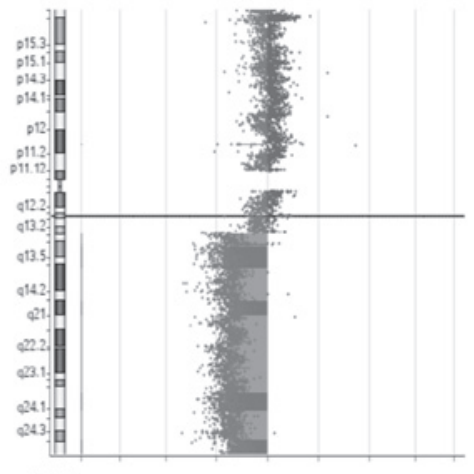

B

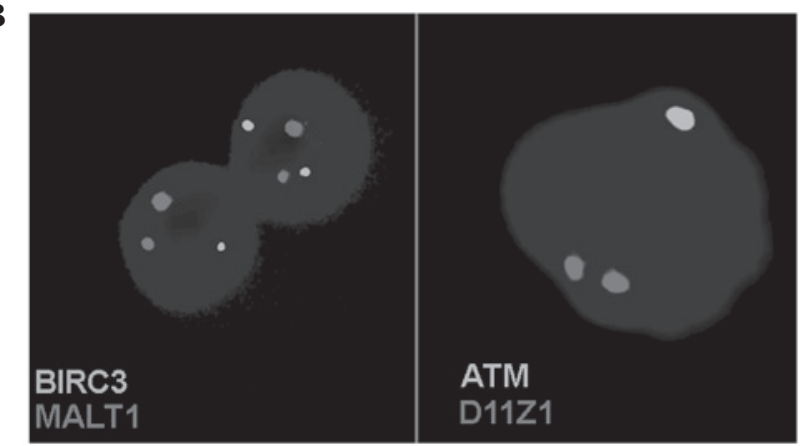

$\# 11$

Figure 3. Results obtained for B-ALL case A-1 by array comparative genomic hybridization and iFISH are summarized. (A) Deletion in 11q22-q23, initially detected by iFISH, resulted in loss of the whole long arm of a chromosome 11. (B) Examples for heterozygote deletions of ATM and BIRC3 detected by iFISH are depicted. iFISH, interphase fluorescence in situ hybridization; ATM, ataxia telangiectasia mutated; BIRC3, baculoviral IAP repeat-containing 3; MALT1, mucosa-associated lymphoid tissue lymphoma translocation gene 1; D11Z1, CEP 11 probe.

was identified as possessing a triploid/hyperdiploid karyotype in the iFISH analysis using CEP 11, 17 and 18 (case A-2, result not shown), as was observed in the cases C-21 and C-22.

The BIRC3 deletion in B-ALL case A-1 was confirmed by $\mathrm{aCGH}$, which reveled that the deletion in the long arm of chromosome 11 covered between chr11:67,773,863 and 134,945,165 (GRCh37/hg19) (Fig. 3). The ATM and BIRC3 genes are located between positions 102,188,181 and $108,239,826$.

\section{Discussion}

The BIRC3 gene, located on 11q22.2, is $\sim 6 \mathrm{Mb}$ centromeric to the $A T M$ gene locus and is considered to be a negative regulator of the non-canonical NF- $\mathrm{B}$ signaling pathway $(13,14) . B I R C 3$ cooperates with tumor necrosis factor receptor-associated factors 2 and 3 , in the same protein complex that negatively regulates the mitogen-activated protein kinase 14 , a serine-threonine kinase and central activator of non-canonical NF- $\kappa B$ signaling (7). In addition, a frequent aberration associated with BIRC3 is the recurrent $\mathrm{t}(11 ; 18)(\mathrm{q} 21 ; \mathrm{q} 21)$ translocation, which involves the mucosa-associated lymphoid tissue lymphoma translocation gene 1 (MALT1), located on 18q21.32. This type of alteration appears in mucosa-associated lymphoid tissue (MALT) lymphoma (15).

The present study regarding BIRC3 copy number variations in 117 CLL and 45 B-ALL patients has revealed several major findings that, to the best of our knowledge, have not been previously reported. Firstly, BIRC3 duplications were detected in 3 cases of CLL, and 2 of these were associated with ATM and MALT1 duplications, in addition to TP53 deletions; BIRC3 amplification was detected in these 2 cases as a result of a hyperdiploid cell clone and has been previously reported in cases of CLL, but is not a frequent event $(16,17)$. In addition, $1 \mathrm{~B}$-ALL patient possessed a duplication of BIRC3 due to partial hyperdiploidy, which is more common in B-ALL compared with CLL, and is associated with good prognosis in pediatric patients (18). A CLL-case with a BIRC3 duplication possessed normal ATM and TP53 copy numbers; however, the duplication was not detected by aCGH, most likely due to the low sensitivity of aCGH for mosaic detection, despite being present in $36 \%$ of the cells. Previous studies on the interaction of BIRC3 with the NF- $\mathrm{NB}$ pathway indicate that $B I R C 3$ duplication may lead to the inactivation of tumor suppressor activity (19-21).

As the predominant morphological feature of CLL is the accumulation of small B lymphocytes (1), B-ALL patients were chosen to be the second group to be tested for BIRC3-alterations in the present study. Therefore the second important finding of the present study is the detection of a BIRC 3 deletion in 1 of the 45 studied B-ALL cases. The aCGH for case A-1 revealed the deletion of almost all of the long arm of chromosome 11, and the most frequent aberrations associated with chromosome 11 in B-ALL patients are structural abnormalities in band 11q23, which harbors the myeloid/lymphoid leukemia gene (22).

Chromosomal deletions involving 11q have been reported in certain subtypes of hematological malignancies, including B-cell CLL, and are associated with a poor prognosis in mantle cell lymphomas or T-cell prolymphocytic leukemia (23). Therefore, the prognosis for the B-ALL patient in the present study may be poor or extremely poor. Additional studies are required to determine the role of BIRC3 in the prognosis of B-ALL patients.

The disruption of BIRC3 is specifically restricted to chemo-refractory cases in progressive CLL patients, and may selectively associate with fludarabine-refractory patients with normal TP53 (7). Therefore, another notable finding of the present study is that $B I R C 3$ abnormalities were associated with TP53 deletion in only 4/117 CLL cases. According to previous studies, the frequency of $B I R C 3$ disruption is low at diagnosis; however, BIRC3 disruptions tend to accumulate among refractory CLL and emerge over time. Patients harboring a BIRC3 disruption typically experience an aggressive disease course, even compared with other clinically aggressive groups $(14,24)$. This aspect of the disease was not the focus of the present study. However, examining BIRC3 duplication cases for the presence of mutations may be interesting for future study.

The application of a BIRC3 probe in iFISH increased the diagnostic yield in CLL and ALL cases. As in MLPA or aCGH by BIRC3-directed iFISH, only gain or loss of copy numbers can be registered. However, to the best of our knowledge, $B I R C 3$ activation by a translocation has not previously been 
reported. Therefore, routine iFISH and MLPA testing in CLL and ALL should be enhanced by a probe specific for BIRC3. iFISH is superior to MLPA as it is able to detect low level mosaics in the probe sample, however, MLPA is more cost-effective (2). A combination of the two approaches, by performing MLPA followed by iFISH in selected cases may be the best compromise if corresponding MLPA sets are available (2).

In conclusion, the hypothesis by Rose-Zerilli et al (25) that BIRC3 deletions are always associated with ATM deletions is questioned at least for a small percentage of cases. As screening of the $B I R C 3$ gene is not routinely undertaken for CLL patients $(2,26)$, the results of the present study suggest that screening may be considered as necessary in the future, particularly to aid in making the correct treatment decisions; particularly, whether to treat with or without fludarabine.

\section{Acknowledgements}

The present study was supported by Katholischer Akademischer Ausländer-Dienst (fellowship to Mr. Eyad Alhourani) and Deutscher Akademischer Austauschdienst (fellowship to Mr. Moneeb A.K. Othman; PROBRAL (grant no., 57054562 to Dr Thomas Liehr; University Partnership Program of Friedrich Schiller University Jena to Dr Thomas Liehr).

\section{References}

1. Rodríguez-Vicente AE, Díaz MG and Hernández-Rivas JM: Chronic lymphocytic leukemia: A clinical and molecular heterogenous disease. Cancer Genet 206: 49-62, 2013.

2. Alhourani E, Rincic M, Othman MA, Pohle B, Schlie C, Glaser A and Liehr T: Comprehensive chronic lymphocytic leukemia diagnostics by combined multiplex ligation dependent probe amplification (MLPA) and interphase fluorescence in situ hybridization (iFISH). Mol Cytogenet 7: 79, 2014.

3. Döhner H, Stilgenbauer S, Benner A, Leupolt E, Kröber A, Bullinger L, Döhner K, Bentz M and Lichter P: Genomic aberrations and survival in chronic lymphocytic leukemia. N Engl J Med 343: 1910-1916, 2000.

4. Gunn SR, Hibbard MK, Ismail SH, Lowery-Nordberg M, Mellink CH, Bahler DW, Abruzzo LV, Enriquez EL, Gorre ME, Mohammed MS and Robetorye RS: Atypical 11q deletions identified by array CGH may be missed by FISH panels for prognostic markers in chronic lymphocytic leukemia. Leukemia 23: 1011-1017, 2009.

5. Greipp PT, Smoley SA, Viswanatha DS, Frederick LS, Rabe KG, Sharma RG, Slager SL, Van Dyke DL, Shanafelt TD, Tschumper RC and Zent CS: Patients with chronic lymphocytic leukaemia and clonal deletion of both $17 \mathrm{p} 13.1$ and $11 \mathrm{q} 22.3$ have a very poor prognosis. Br J Haematol 163: 326-333, 2013.

6. Campregher PV and Hamerschlak N: Novel prognostic gene mutations identified in chronic lymphocytic leukemia and their impact on clinical practice. Clin Lymphoma Myeloma Leuk 14: 271-276, 2014.

7. Rossi D, Fangazio M, Rasi S, Vaisitti T, Monti S, Cresta S, Chiaretti S, Del Giudice I, Fabbri G, Bruscaggin A, et al: Disruption of BIRC3 associates with fludarabine chemorefractoriness in TP53 wild-type chronic lymphocytic leukemia. Blood 119: 2854-2862, 2012.

8. Rossi D, Fangazio M and Gaidano G: The spectrum of genetic defects in chronic lymphocytic leukemia. Mediterr J Hematol Infect Dis 4: e2012076, 2012 .

9. Rossi D, Rasi S, Spina V, Bruscaggin A, Monti S, Ciardullo C, Deambrogi C, Khiabanian H, Serra R, Bertoni F, et al: Integrated mutational and cytogenetic analysis identifies new prognostic subgroups in chronic lymphocytic leukemia. Blood 121: 1403-1412, 2013.
10. Puiggros A, Blanco G and Espinet B: Genetic abnormalities in chronic lymphocytic leukemia: Where we are and where we go. BioMed Res Int 2014: 435983, 2014.

11. Hallek M, Cheson BD, Catovsky D, Caligaris-Cappio F, Dighiero G, Döhner H, Hillmen P, Keating MJ, Montserrat E, Rai KR and Kipps TJ; International Workshop on Chronic Lymphocytic Leukemia: Guidelines for the diagnosis and treatment of chronic lymphocytic leukemia: A report from the International Workshop on Chronic Lymphocytic Leukemia updating the National Cancer Institute-Working Group 1996 guidelines. Blood 111: 5446-5456, 2008.

12. Othman MA, Rincic M, Melo JB, Carreira IM, Alhourani E, Hunstig F, Glaser A and Liehr T: Novel cryptic three-way translocation $\mathrm{t}(2 ; 9 ; 18)(\mathrm{p} 23.2 ; \mathrm{p} 21.3 ; \mathrm{q} 21.33)$ with deletion of tumor suppressor genes in 9p21.3 and 13q14 in a T-cell acute lymphoblastic leukemia. Leukemia Res Treat 2014: 357123, 2014.

13. Rossi D, Ciardullo C, Spina V and Gaidano G: Molecular bases of chronic lymphocytic leukemia in light of new treatments. Immunol Lett 155: 51-55, 2013.

14. Cortese D, Sutton LA, Cahill N, Smedby KE, Geisler C, Gunnarsson R, Juliusson G, Mansouri L and Rosenquist R: On the way towards a 'CLL prognostic index': Focus on TP53, BIRC3, SF3B1, NOTCH1 and MYD88 in a population-based cohort. Leukemia 28: 710-713, 2014.

15. Morgan JA, Yin Y, Borowsky AD, Kuo F, Nourmand N, Koontz JI, Reynolds C, Soreng L, Griffin CA, Graeme-Cook F, et al: Breakpoints of the $\mathrm{t}(11 ; 18)(\mathrm{q} 21 ; \mathrm{q} 21)$ in mucosa-associated lymphoid tissue (MALT) lymphoma lie within or near the previously undescribed gene MALT1 in chromosome 18. Cancer Res 59: 6205-6213, 1999.

16. Shao L, Kang SH, Li J, Hixson P, Taylor J, Yatsenko SA, Shaw CA, Milosavljevic A, Chang CC, Cheung SW and Patel A: Array comparative genomic hybridization detects chromosomal abnormalities in hematological cancers that are not detected by conventional cytogenetics. J Mol Diagn 12: 670-679, 2010.

17. Specchia G, Albano F, Anelli L, Storlazzi CT, Monaco M, Capalbo S, Rocchi M and Liso V: Concomitant tetrasomy $3 \mathrm{q}$ and trisomy 18 in CD5(-), CD13(+) chronic lymphocytic leukemia. Cancer Genet Cytogenet 133: 160-163, 2002.

18. Kebriaei P, Anastasi J and Larson RA: Acute lymphoblastic leukaemia: Diagnosis and classification. Best Pract Res Clin Haematol 15: 597-621, 2002.

19. Ryan KM, Ernst MK, Rice NR and Vousden KH: Role of NF-kappaB in p53-mediated programmed cell death. Nature 404: 892-897, 2000.

20. Keller U, Huber J, Nilsson JA, Fallahi M, Hall MA, Peschel $\mathrm{C}$ and Cleveland JL: Myc suppression of Nfkb2 accelerates lymphomagenesis. BMC Cancer 10: 348-358, 2010.

21. Liu F, Bardhan K, Yang D, Thangaraju M, Ganapathy V, Waller JL, Liles GB, Lee JR and Liu K: NF- $x$ B directly regulates Fas transcription to modulate Fas-mediated apoptosis and tumor suppression. J Biol Chem 287: 25530-25540, 2012.

22. Cox MC, Panetta P, Lo-Coco F, Del Poeta G, Venditti A, Maurillo L, Del Principe MI, Mauriello A, Anemona L, Bruno A, et al: Chromosomal aberration of the 11q23 locus in acute leukemia and frequency of MLL gene translocation: Results in 378 adult patients. Am J Clin Pathol 122: 298-306, 2004

23. Monni O and Knuutila S: 11q deletions in hematological malignancies. Leuk Lymphoma 40: 259-266, 2001.

24. Strefford JC, Sutton LA, Baliakas P, Agathangelidis A, Malčíková J, Plevova K, Scarfó L, Davis Z, Stalika E, Cortese D, et al: Distinct patterns of novel gene mutations in poor-prognostic stereotyped subsets of chronic lymphocytic leukemia: The case of SF3B1 and subset \#2. Leukemia 27: 2196-2199, 2013.

25. Rose-Zerilli MJ, Forster J, Parker H, Parker A, Rodríguez AE, Chaplin T, Gardiner A, Steele AJ, Collins A, Young BD, et al: ATM mutation rather than BIRC3 deletion and/or mutation predicts reduced survival in 11q-deleted chronic lymphocytic leukemia: Data from the UK LRF CLL4 trial. Haematologica 99: 736-742, 2014.

26. Goorha S, Glenn MJ, Drozd-Borysiuk E and Chen Z: A set of commercially available fluorescent in-situ hybridization probes efficiently detects cytogenetic abnormalities in patients with chronic lymphocytic leukemia. Genet Med 6: 48-53, 2004. 